\title{
$\mathrm{PH} 9 \mathbf{8}_{\text {actualiad }}$
}

\section{Caminos y senderos, fuentes de desarrollo y lucha contra la despoblación rural en Andalucía}

En 2017, el Parlamento de Andalucía aprueba la Ley de Regulación de los Senderos de la Comunidad Autónoma de Andalucía. Como resultado, hoy existen más de 10.000 kilómetros señalizados y homologados en todo el territorio andaluz. En 2018, llega al mismo Parlamento una Proposición de Ley sobre Caminos Públicos Rurales que, sin embargo, no llega a ser aprobada, quedando pendiente la protección de 60.000 kilómetros de caminos públicos existentes en Andalucía, muchos actualmente usurpados ilícitamente por propietarios de tierras colindantes. Los autores hacen balance de esta situación considerando los senderos y caminos como recursos patrimoniales para la diversificación de la actividad económica y dinamización social en el medio rural. Y su protección, como un mecanismo de fijación de la población y de conservación medioambiental.

David Moscoso Sánchez | Dpto. de Sociología, Universidad Pablo de Olavide José María Nasarre Sarmiento | Dpto. de Derecho de la Empresa, Universidad de Zaragoza

URL de la contribución <www.iaph.es/revistaph/index.php/revistaph/article/view/4424>

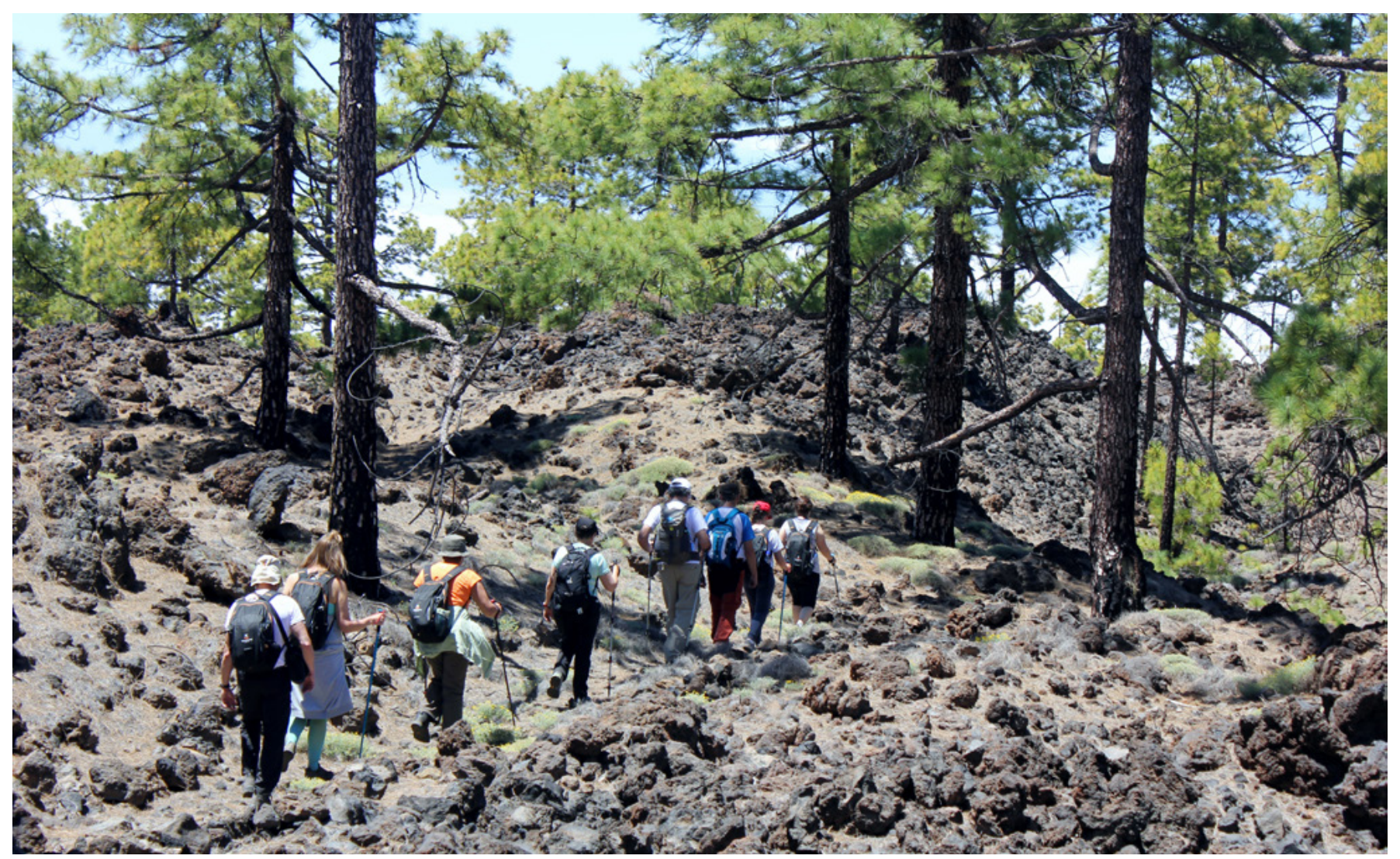

Grupo de senderistas de la Federación Española de Deportes de Montaña y Escalada realizando senderismo por el entorno del Parque Nacional del Teide | foto José María Nasarre 
Durante la X Legislatura del Parlamento de Andalucía, la actividad parlamentaria propició la Ley de Regulación de los Senderos de la Comunidad Autónoma de Andalucía y la Ley de Caminos Públicos Rurales en Andalucía, sendas iniciativas destinadas a recuperar y poner en valor el patrimonio viario público andaluz, en parte motivada por la movilización de ciertos agentes sociales y, en parte, por la sensibilidad de algunos grupos parlamentarios. La primera se aprueba el 20 de abril de 2017; no así la segunda que, si bien fue admitida a trámite por mayoría de la Cámara, no concluyó su tramitación por disolución del Parlamento.

En este sentido, cabe señalar que la primera de las iniciativas no sólo contó con el apoyo unánime de todos los grupos parlamentarios, lo que pone de relieve el consenso que desprende la puesta en valor de los senderos de uso turístico y deportivo, sino, más allá aún, aunó las voluntades de numerosos agentes del ámbito deportivo, cultural, económico y social. No en vano, la tramitación de la citada Ley de Regulación de Senderos contó con el apoyo de federaciones deportivas del ámbito del montañismo y la caza (FEDAMON, FEDME y FAC), las principales organizaciones profesionales agrarias (UPA, COAG y ASAJA), los colectivos ecologistas y plataformas ciudadanas de defensa de caminos públicos (Ecologistas en Acción, Plataforma Ibérica de Caminos Públicos, Asociación Andaluza de Vías Verdes y A Desalambrar), así como asociaciones de carácter cultural (Federación Andaluza de Asociaciones de Amigos del Camino de Santiago), entre otras muchas.

Ambas iniciativas partían del reconocimiento de que los caminos y senderos rurales son parte integrante del dominio público viario que tiene en la actualidad más funciones y usos que los tradicionales. En efecto, representan en sí mismos una expresión rotunda del acervo cultural viario de nuestro país, en tanto que actividades como la agricultura, la ganadería, la forestal, la trashumancia o la caza, han girado tradicionalmente en torno a los llamados caminos rurales. Por tanto, estos necesitan ser mantenidos, protegidos, ordenados y conservados. Y, por ese motivo, desde años atrás, se viene demandando por sendos agentes sociales y económicos (asociaciones ecologistas, organizaciones agrarias

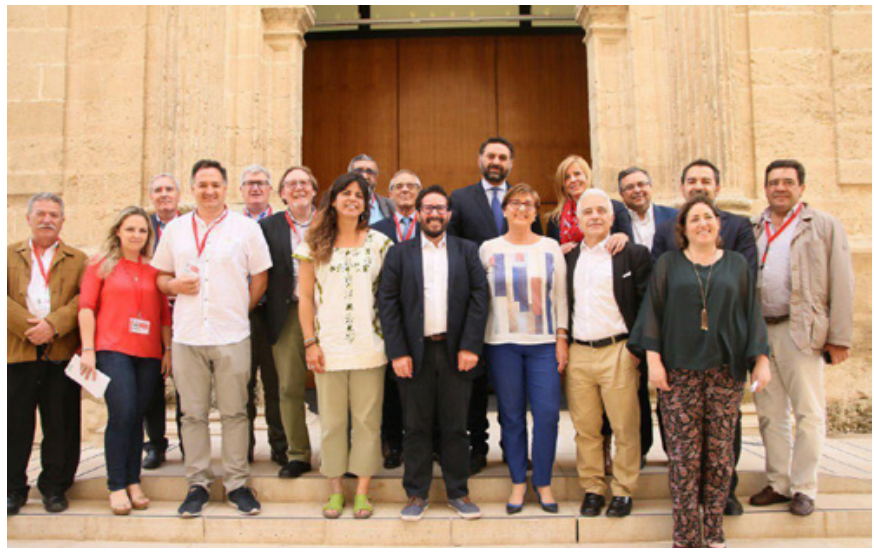

Foto de familia del gobierno andaluz, los grupos parlamentarios y los agentes sociales, tras la aprobación de la Ley de Senderos de Andalucía, el 27 de mayo de 2017, en el Parlamento de Andalucía | foto Francisco Artacho

como UPA o COAG, plataformas ciudadanas de defensa de caminos públicos, etc.) la necesidad de dotar a las administraciones andaluzas de una norma que potencie esas competencias, como parte del desarrollo sostenible del medio rural andaluz. Sólo los grandes propietarios de tierras, representados principalmente en ASAJA, y los titulares de grandes fincas de caza, agrupados sobre todo en Ateca, han sido en este tiempo el principal frente de oposición a estas leyes y, en definitiva, a la recuperación, puesta en valor, vigilancia y mantenimiento del carácter público de los caminos rurales y los senderos.

Las dos iniciativas parlamentarias han puesto de relevancia el papel que la difusión del senderismo ha ejercido en los últimos años en ese reconocimiento de los valores del patrimonio viario rural. Porque el senderismo reúne unas características que van más allá de los valores que como deporte le son propios, habiéndose convertido en todo un motor económico y social en muchas áreas rurales y espacios naturales.

Ciertamente, el uso turístico y no sólo deportivo de los senderos genera un importante valor para las principales economías de Europa, destacando en Reino Unido, donde esta actividad tiene un impacto económico de 6.500 millones de euros al año, según la Comisión Europea (IMPACTO, 2014: 16 y ss.). En este sentido, se debe valorar la oportunidad que suponen los 100 millones de senderistas-turistas que hay actualmente en 


\section{$\mathrm{PH} 988$}

Europa para la generación de empleo de calidad y la dinamización económica del entorno rural en Andalucía.

Según los datos publicados por el Gobierno de la nación, en España existen 2 millones de senderistas habituales y 16 millones anuales de visitantes a espacios naturales protegidos, entre los que el senderismo se ha convertido en la principal demanda de uso y disfrute (ANUARIO, 2019; DATOS, 2019). Además, esta actividad se ha convertido en el tercer deporte más practicado en nuestro país, según el Consejo Superior de Deportes (CSD). Tan solo en Aragón, el senderismo genera un impacto directo de 200 millones de euros al año con motivo del desarrollo de esta actividad económica.

$\mathrm{Y}$, aunque bien es cierto que con anterioridad siete comunidades autónomas habían abordado la señalización de senderos mediante Decreto, la norma andaluza fue la primera en otorgar a esta materia rango de Ley (en la que, además, se han inspirado otras normas pos- teriores en Baleares y Región de Murcia). Por tanto, el Parlamento de Andalucía se puso a la vanguardia con el primer debate acerca de las implicaciones ambientales, deportivas o turísticas del senderismo, abriendo así un camino novedoso para la consolidación de los usos tradicionales de los senderos y la incorporación de los nuevos usos de este importante patrimonio público.

Por todo lo anterior, Andalucía cuenta con un extraordinario potencial para multiplicar el valor añadido de la práctica del senderismo en sus espacios naturales y áreas rurales, gracias a la Ley 3/2017, de 2 de mayo, de Regulación de los Senderos en la Comunidad Autónoma de Andalucía, así como al desarrollo de la misma con el Decreto 67/2018, de 20 de marzo, por el que se regulan los senderos de uso deportivo en Andalucía, contando actualmente con más de 10.000 kilómetros señalizados y homologados. Además, nuestra comunidad alberga más de 500 kilómetros de vías verdes y 8.000 kilómetros de vías pecuarias deslindadas, que podrían llegar a ser 31.000 de deslin-

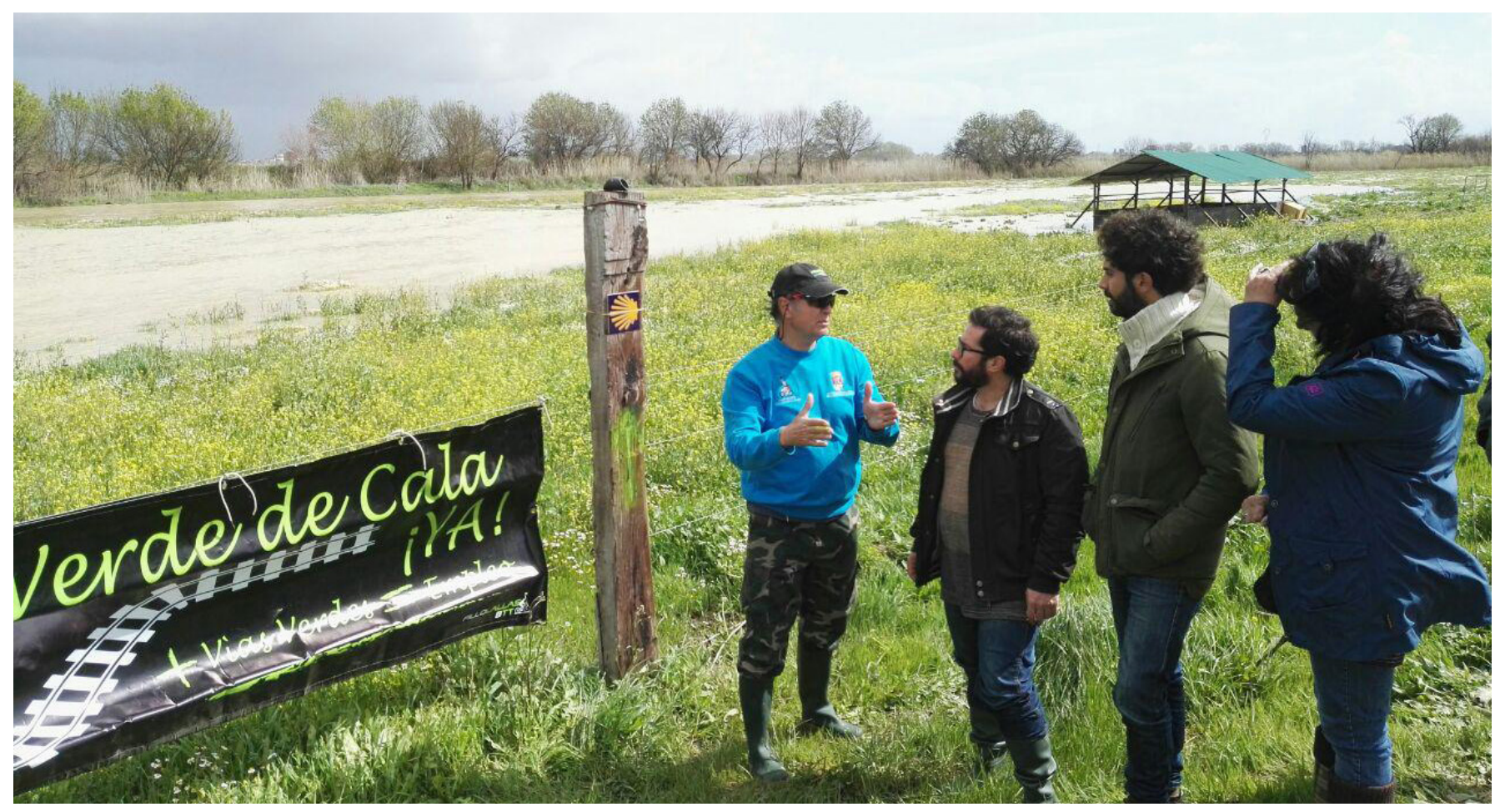

Reunión con los representantes de la Asociación Vías Verdes en la ubicación del antiguo trazado del llamado Tren de la Cala, hoy día roturada y usurpada por propietarios de tierras colindantes | foto Fonsi de Olallareal 


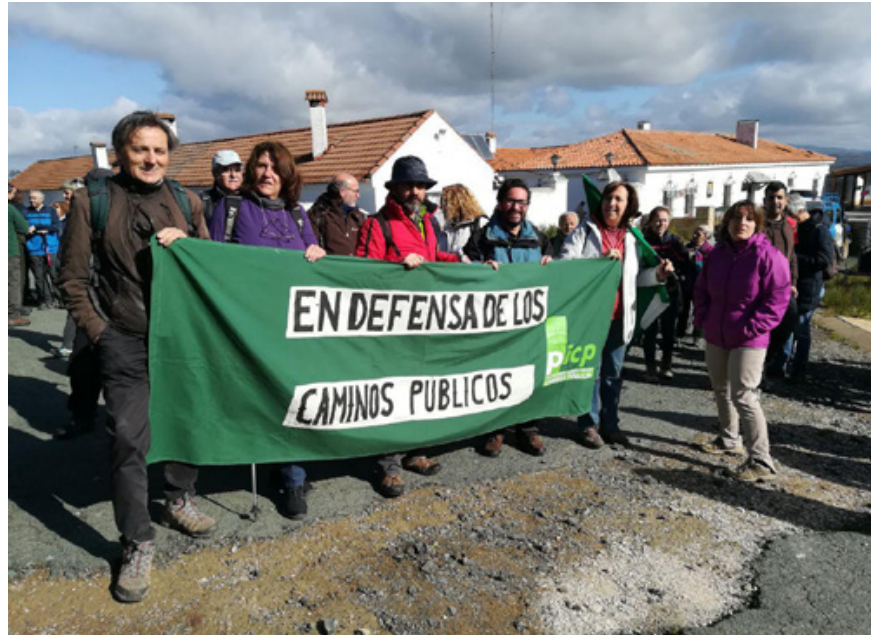

Manifestación en defensa de los caminos públicos en la vía pecuaria Salto de la Trocha, entre Castilblanco de los Arroyos y Almadén de la Plata (Sevilla), hoy usurpada por propietarios de tierras colindantes | foto Juan Carlos Romero

darse todas las vías pecuarias andaluzas, un dato que está muy lejos de los compromisos adquiridos por parte de la administración andaluza con la Comisión Europea, por falta de voluntad política. Asimismo, por Andalucía discurren 1.116 kilómetros del Camino de Santiago y alrededor de 23.000 kilómetros de senderos forestales catalogados actualmente por la Consejería con competencias en medio ambiente de la Junta.

Los $60.000 \mathrm{~km}$ de caminos públicos de Andalucía, muchos actualmente usurpados ilícitamente por propietarios de tierras colindantes, también hubieran podido sumarse a los magníficos activos de esta tierra, de haberse aprobado finalmente el dictamen de la Proposición de Ley relativa a caminos públicos rurales de Andalucía, quedando pendiente como asignatura en el futuro.

Ciertamente, la usurpación del patrimonio comunal viario, como son vías pecuarias, cordeles, cañadas reales, senderos y veredas, de naturaleza pública, no pueden seguir encontrándose sujetos a su alteración, roturación o cierre, por parte de particulares, en perjuicio del interés general y el patrimonio colectivo - de la misma forma que no se entendería que un particular se apropiase de una calle, un parque o una plaza de su pueblo, o de un colegio o un hospital públicos.
En conclusión, con esta riqueza patrimonial y una gestión eficiente y coordinada de dichos recursos, Andalucía puede y debe convertirse en una potencia en el ámbito del senderismo, apostando por este sector económico como estrategia para la cohesión territorial, la fijación de población rural y la conservación del medioambiente.

\section{BIBLIOGRAFÍA}

- ANUARIO de estadísticas deportivas (2019) [en línea] Ministerio de Cultura y Deporte, 2019 <https://www. culturaydeporte.gob.es/servicios-al-ciudadano/estadisticas/ deportes/anuario-de-estadisticas-deportivas.html> [Consulta: 03/09/2019]

- IMPACTO económico y social del programa de caminos naturales (2014) [en línea] Ministerio de Agricultura, Alimentación y Medio Ambiente, 2014 <https://www.mapa.gob. es/es/desarrollo-rural/temas/caminos-naturales/5a\%20-\%20 ImpactoEconomicoSocialCNyVV_DEF4_tcm30-149315.pdf> [Consulta: 03/09/2019]

- DATOS de visitantes a los parques nacionales 1996-2017 (2019) [en línea] Ministerio para la Transición Ecológica, 2019 <https://www.miteco.gob.es/es/red-parques-nacionales/la-red/ gestion/visitantes.aspx> [Consulta: 03/09/2019] 